\title{
¿Qué hace una escuela como tú en tu siglo como este? Rafael Feito Alonso. Madrid: Los Libros de la Catarata, 2020
}

\author{
Javier Rujas Martínez-Novillo (iD \\ Universidad de Burgos, España \\ jrujas@ubu.es
}

En su último libro, Rafael Feito nos propone un diagnóstico actual y personal del sistema educativo español. Con un lenguaje claro y accesible para el lector no especializado, alejado de la frialdad y el formalismo habituales de los informes y de los artículos científicos, este ensayo examina algunos de los problemas la educación actual, pero también entra en el terreno de las propuestas: se propone sugerir cambios para que el sistema educativo garantice una educación de calisdad para todos. La argumentación del autor alterna, así, datos y resultados de estudios con opiniones propias. Las propuestas realizadas por Feito podrán juzgarse más o menos adecuadas, algunas quizá polémicas, pero logran generar debate y reflexión sobre la educación existente y sobre la que sería posible o deseable. Esta intención venía anunciada ya desde la publicación hace catorce años de Otra escuela es posible y probablemente alcanza su forma más acabada en este trabajo.

El tono divulgativo, crítico y propositivo del trabajo de Feito no aparece reñido, como ocurre a veces con los ensayos generalistas sobre educación que abundan en las librerías, con la fundamentación de sus argumentos en una amplia literatura científica que refleja el conocimiento y la experiencia acumulados durante años de docencia e investigación en el ámbito de la sociología de la educación. En este sentido, quienes hemos pasado por las aulas de Feito como alumnos y/o le hemos leído a lo largo de los años, encontramos muchos ecos de temas tratados previamente por el autor, ampliados y apoyados en investigaciones clásicas y recientes: qué se enseña, cómo se enseña, cómo se agrupa al alumnado, la jornada escolar, la participación de las familias en la escuela, el profesorado o las escuelas democráticas. A ellos se suman otros de actualidad que han despertado su interés más recientemente, como los deberes o las pruebas externas. El texto que reseñamos es, por tanto, un trabajo comprensivo y ambicioso, pues plantea una visión de conjunto de la educación que abarca muy diversos temas.

El título del libro, además de hacer resonar en el lector/a la icónica canción de Burning, evoca una idea conocida en el mundo educativo y popularizada en las últimas décadas por divulgadores como Ken Robinson: la escuela tal y como la conocemos es una institución creada en un contexto histórico y social concreto, la revolución industrial, que se encuentra, sin embargo, en el siglo XXI con una sociedad, unos jóvenes y unas necesidades sociales muy distintos a las de entonces. Sin duda, la institución escolar lleva la impronta de ese pasado y arrastra una fuerte inercia institucional, aunque la exageración de las continuidades puede también llevarnos a no ver los muchos cambios que ha conocido la educación en el último medio siglo. Feito argumenta que, en la actualidad, persiste el sesgo academicista y descontextualizado del conocimiento escolar, pues el sistema educativo sigue tomando como referencia al alumnado que llegará a la universidad -aunque haya aumentado, aún una minoría- y expulsa progresivamente a quienes no obtienen "buenos" resultados (no pocas veces con otras habilidades no reconocidas o valoradas por la escuela). 
Como explica el autor, la enorme mayoría de los jóvenes depende hoy del sistema educativo para obtener un empleo y asegurar su subsistencia, algo más difícil para aquellos que no consiguen al menos un título de secundaria superior. También por arriba se da un problema de sobrecualificación: no hay tantos puestos de trabajo cualificados como titulados universitarios. Feito se hace eco de las proyecciones que dicen que estos serán los puestos que más crecerán en los próximos años, aunque los discursos "futuristas" sobre la educación y el empleo pueden resultar problemáticos. ¿Son fiables estas predicciones? ¿No reflejan más un deseo que una realidad? ¿Acaso no persiste con fuerza una estructura del mercado de trabajo en España que se resiste a esta transformación? ¿Hasta qué punto podemos decir que todos los empleos (los actuales y los del futuro) requieren aprendizaje a lo largo de toda la vida, trabajo en equipo, desarrollar argumentos y comunicar? ¿No es esta una visión acorde con los empleos intelectuales, no manuales, pero poco representativa de los empleos de clase obrera? Estas dudas difícilmente pueden resolverse por adelantado, como pretenden los discursos proféticos, y requerirían más estudios desde las ciencias sociales.

Feito también argumenta que, aunque hay consenso en que la escuela debe contribuir a construir una ciudadanía democrática, no está claro que esta ofrezca espacios para el desarrollo de hábitos democráticos. Tampoco garantiza el éxito escolar para todos, pues, pese al aumento del nivel educativo de la población, los datos siguen mostrando la influencia de las desigualdades socioeconómicas en los resultados escolares, a las que se suman las relacionadas con las migraciones.

Además, según el autor, la economía se basa cada vez más en el conocimiento y este se produce de forma cada vez más acelerada, al tiempo que se vuelve más provisional. En este contexto, no está tan claro lo que debe enseñar la escuela, más allá de los aprendizajes básicos. Enlaza, así, con la sociología del currículo (capítulo 2): los contenidos escolares siguen una secuencia basada en una concepción lineal del desarrollo psicológico y parten de la idea de que se aprende mejor a partir de fragmentos sucesivos, a pesar de haberse desmentido esta visión. El currículo sería, según Feito, excesivo, fragmentario, arbitrario, y estaría jerarquizado y desfasado. Además, el modo de enseñar se basa en la premisa (irreal) de que el profesorado debe captar y mantener la atención del alumnado en todo momento y este debe estar sentado y en silencio, absorbiendo el conocimiento, observando las normas, respetando la autoridad, realizando tareas y siendo evaluado durante un elevado número de horas. En España, en comparación con otros países, los estudiantes recurren más a la memorización que a la reflexión o a la elaboración sobre lo aprendido, algo más frecuente cuanto más bajamos de clase social y favorecido por las prácticas y expectativas docentes en los distintos centros educativos, que necesariamente adaptan el currículo a su público ( $y$ a las ideas que tienen sobre este). Dominan la palabra del profesor y el libro de texto, y los "buenos" alumnos acaban siendo quienes dan al profesorado lo que quiere. El autor ve, en este contexto, el aprendizaje por competencias como una solución, pero queda en el aire hasta qué punto esta concepción promovida por la UE llegó a aplicarse y se aplica en la actualidad, y hasta qué punto tuvo los efectos buscados.

El libro también se hace eco del debate y la investigación generados alrededor de los deberes (capítulo 4). Feito revisa los trabajos sobre el tema y muestra que nos encontramos con más incógnitas que respuestas. Las tareas escolares en casa no mejoran el rendimiento de los alumnos de primaria, aunque mejoran algo el de los de secundaria inferior y algo más el de los de secundaria superior. En España, dedicamos más tiempo de media que otros países a esta actividad, pero no se traduce en mejores competencias. Si desde el franquismo hasta mediados de los 80 se trató de regular que los deberes fuesen algo excepcional, coordinado para evitar la sobrecarga y no meramente mecánico y repetitivo, no parece que esto se haya llegado nunca a aplicar completamente. Es más, se dan discrepancias importantes en la percepción que tienen docentes, padres y alumnos de la 
carga de deberes, y los estudios arrojan resultados dispares. Aunque la mayoría piensa que son necesarios y positivos, hay matices y muchos los consideran excesivos. Conforme se avanza en el sistema, decrece el apoyo de los padres en las tareas, aumenta el estrés que estas generan y se reduce la percepción de su utilidad. No obstante, hablar en genérico es problemático pues oculta las diferencias de clase social: el apoyo familiar en las tareas y el recurso a profesores particulares o academias difiere según el capital económico y cultural de la familia, y las AMPA de clase media-alta están más de acuerdo con la necesidad de hacer deberes fuera del centro escolar que las de clase trabajadora. Faltan en España estudios que profundicen en el análisis de estas diferencias y sus razones.

El capítulo 5 analiza otro aspecto muy debatido en educación: las pruebas de evaluación externas. Aunque pretenden ofrecer una imagen más objetiva de las competencias adquiridas por los estudiantes, tienen efectos perversos: se acaba enseñando para la prueba; se limitan los conocimientos a lo fáctico y a las competencias más valoradas por la escuela, dejando de lado otras; la exigencia en las pruebas varía de un año a otro; se etiqueta a los alumnos en función de sus resultados previstos y se incrementa su estrés. Los exámenes externos acaban definiendo "lo que cuenta como conocimiento legítimo" ( $p$. 123), controlando los modos de enseñar y empujando al fraude, sin que haya pruebas claras de que mejoren los resultados de los sistemas educativos.

Feito se adentra también en el debate heterogeneidad-homogeneidad (capítulo 6), analizando las formas de agrupación y separación del alumnado en un mismo centro y entre centros. Desmonta algunos de los supuestos en los que se basan las propuestas de segregación en función del desempeño a ciertas edades. Los sistemas que segregan temprano no necesariamente tienen mejores resultados ni son más equitativos. El rendimiento de los alumnos puede cambiar, la inteligencia es especialmente plástica hasta los 25 años y la adolescencia se ha prolongado en las últimas décadas. La concepción escolar de la inteligencia, además, se restringe a las dimensiones lógico-matemática y lingüística, obviando otras inteligencias o competencias. Las formas de segregación institucional, como la separación entre Matemáticas académicas y aplicadas, los Programas de Mejora del Aprendizaje y el Rendimiento (PMAR), o la configuración de cuarto de ESO en función de los itinerarios postobligatorios, plantean dudas sobre la equidad y la comprensividad (formal) del sistema. La heterogeneidad no necesariamente perjudica a los "mejores" alumnos, pero la separación sí tiende a perjudicar a los que tienen dificultades, al reducirse el currículo, las expectativas docentes y su autoestima. Feito también examina la separación en itinerarios académicos y profesionales, proponiendo algunas críticas interesantes al discurso que se ha impuesto en los últimos años sobre la necesidad de promover la FP, especialmente el Grado Medio, como solución al abandono y a la "falta" de titulados medios en España.

En el capítulo 7, Feito aborda otro tema muy debatido y polémico, la formación del profesorado y el acceso a la profesión docente, valorando distintas alternativas. Aunque en esta parte no encontramos un análisis en profundidad de la condición de este grupo profesional, su cultura y sus cambios, en el libro hay varias referencias puntuales a estos temas. Feito concluye el capítulo con una serie de características que definirían a un "buen" profesor, identificándolo con aquél que es percibido como "muy comprometido" por el resto del equipo docente. Las definiciones sobre lo que es ser un "buen" profesor son, sin embargo, heterogéneas, incluso contradictorias, y dependen de distintos factores, así como de a quién se pregunte. Sería interesante estudiar este tema con más profundidad desde un punto de vista no normativo, pues suele darse por hecho qué es ser un buen profesor, sin indagar y problematizar lo que puede significar. En la actualidad, además, la idealización mediática de algunos docentes, convertidos en gurús educativos, los premios a los "mejores" profesores y ciertas políticas educativas y prácticas de evaluación de la 
labor docente pueden terminar por imponer una particular definición del "buen" profesor con efectos que habría que explorar.

Otro de los temas clásicos que se aborda en el libro es el de la relación familias-escuela (capítulo 8). Aunque es frecuente en el profesorado la percepción de que la familia delega su labor educativa en la escuela, no se preocupa por sus hijos, se entromete en el trabajo docente o es responsable del fracaso escolar, la gran mayoría de niños y niñas considera que sus padres se interesan por sus estudios, les cuentan sus problemas en el colegio y justifican los castigos paternos. Como señala Feito, la participación de los padres en la escuela empieza a despertar interés y preocupación cuando se extiende la escolarización y se rompe el pacto implícito previo entre los centros escolares y las familias más escolarizadas, con quienes los docentes "compartían un universo cultural" (p. 184). Hoy, sin embargo, siguen siendo muchas las limitaciones de la participación y la llamada libertad de elección de centro tiende a reforzar las desigualdades.

El autor analiza también dos cuestiones relativas a los tiempos escolares: el debate sobre la jornada escolar y la menos debatida organización del calendario (capítulo 9). Argumenta que sería necesario repensarlas y organizarlas en función de lo que enseña la investigación acerca de los descansos, la concentración y el rendimiento de los estudiantes, y menos en función de intereses corporativos o familiares particulares.

Para finalizar, Feito propone las "escuelas democráticas" como ideal al que aspirar (capítulo 10), ofreciendo ejemplos de diversos centros educativos que fomentan el gusto por investigar (trabajando por proyectos, globalizando el currículo, usando TIC y bibliotecas, y conectando con su entorno), el trabajo en equipo y la convivencia democrática. Queda abierta la cuestión de si es posible, y en qué condiciones, que los centros ordinarios de distintas etapas implanten estas prácticas desarrolladas por centros excepcionales con características especiales. El libro concluye reafirmando el "desfase" de la institución escolar en la sociedad actual, invocando al profesorado como agente del cambio educativo y con una crítica de aquellas visiones que reducen este cambio al mero retorno a una idealizada situación pre-LOMCE o a un nuevo cambio legal, que, como los anteriores, amenazaría con modificar normativas sin transformar la práctica educativa.

En síntesis, el libro que reseñamos ofrece una buena panorámica de la situación del sistema educativo español y de los temas educativos que más debate suelen generar en el espacio público. Además de diagnosticar y proponer, señala diversas cuestiones que la investigación debería analizar o profundizar y plantea debates pendientes. Podría objetarse al texto que no se abordan algunos temas clásicos y centrales para la comprensión del funcionamiento del sistema educativo en nuestra sociedad y para poder evaluar su equidad, como son las desigualdades de clase, género y etnia. Estas últimas son las menos presentes en el texto, pero el lector/a encontrará referencias a las otras dos a lo largo de los diversos capítulos. Si bien al lector especializado alguna cuestión le puede parecer esbozada o menos desarrollada, resulta inevitable y comprensible en un texto que aborda muchos temas distintos y que busca hacerlo de forma accesible a todo el mundo. Esto último lo convierte además en un material útil para usar como apoyo en la enseñanza de la sociología de la educación y para lectura de los docentes (futuros y actuales) de todas las etapas educativas, además de en una lectura informativa e interesante para cualquier persona interesada en educación. 